\title{
A Multifaceted Approach to the AIAA Foundation Undergraduate Team Aircraft Design Competition
}

\author{
Russell M. Cummings* \\ \& \\ Aaron R. Byerley ${ }^{+}$ \\ Department of Aeronautics \\ United States Air Force Academy \\ USAF Academy, CO 80840
}

\begin{abstract}
$\underline{\text { Abstract }}$
A multifaceted, novel approach was used to help students create entries for the AIAA Foundation Undergraduate Team Aircraft Design

Competition. Each entry involved the design, analysis, construction, and testing of the aircraft. Three groups were involved for each airplane: the first group was responsible for the airframe, the second group was responsible for the engine, and the third group was responsible for the construction and flight testing of a radiocontrolled flying model. There was an overall Chief Executive Officer who insured that engineairframe integration issues were addressed. Students from a variety of majors, both technical and non-technical, participated in various aspects of the project. This approach is seen as one method to give students a multidisciplinary approach to design and problem solving.
\end{abstract}

\section{Introduction}

A dilemma has long existed in engineering curricula-how to give students a truly multidisciplinary experience while designing complex systems. Many engineering programs can certainly claim that their students see design problems from a variety of viewpoints, but including non-engineering perspectives can be difficult (or appear to be impossible). How can business perspectives, ethical issues, environmental concerns, and political considerations be appropriately added to an already full curriculum?

*Distinguished Visiting Professor of Aeronautics, on leave from the Aerospace Engineering Department, California Polytechnic State University. Associate Fellow, AIAA. + Professor. Associate Fellow, AIAA.
In examining the literature we found that the observations of Robert R. Furgason were very true:

One continual comment, especially from employers, is that our engineering graduates are well prepared in the quantitative aspects of the scientific, mathematical, and engineering components of their education, but they often lack what we might term the 'soft' or 'people' skills; that is, the ability to communicate effectively - write, speak, and listen; the ability to work effectively in teams; an appreciation of the economic, environmental, safety, and social factors present in most settings that often dictate the approach that is used; and a realization of the political environment in which they work - both internal and external. In education, we stress the 'right answer' approach and our graduates do not have a good appreciation that most things we deal with are ambiguous and we seek best answers involving many subjective elements. Our curricula should be modified to incorporate these aspects into the educational process [1].

While not all of these observations pertain to all engineering programs, most engineering programs probably could make improvements based on many of the items mentioned above.

The government, industry, and ABET have seen certain aspects of this problem over the years and consequently recommended that engineering programs incorporate design throughout their curricula (ABET evaluation criteria of the 1990s required this). Finally, ABET instituted EC 2000 , a set of outcomes for engineering programs that requires the following [2]: 
Engineering programs must demonstrate that their graduates have:
a) an ability to apply knowledge of mathematics, science, and engineering
b) an ability to design and conduct experiments, as well as to analyze and interpret data
c) an ability to design a system, component, or process to meet desired needs
d) an ability to function on multi- disciplinary teams
e) an ability to identify, formulate, and solve engineering problems
f) an understanding of professional and ethical responsibility
g) an ability to communicate effectively
h) the broad education necessary to understand the impact of engineering solutions in a global and societal context
i) a recognition of the need for, and an ability to engage in life-long learning
j) a knowledge of contemporary issues
k) an ability to use the techniques, skills, and modern engineering tools necessary for engineering practice.

While most engineering programs are considered to be quite good at many of these outcomes, several of the requirements pose a difficult challenge for many engineering faculty members. Specifically, how do engineering programs that are traditionally "stove piped" into disciplines offer a true multi-disciplinary team experiences to their students? How do they educate students as aeronautical systems engineers, with an understanding of how an aircraft should be designed, how an aircraft should be built, how the two relate to each other, and how all of that functions in a modern world [3]?

The purpose of this paper, and the curricular experiment that forms the basis for it, is to determine if there is a way to add the "nonengineering" aspects of education into a design course without unduly diluting the design skills that students need to acquire. We wanted to find out if students could be exposed to a variety of professional practice issues, including working as a team, data collection and analysis, oral and written communications, market analysis, and ethical treatment of engineering decision making. Finally, we wanted to find out how to achieve all of these goals in a way that insured that the course was meaningful to everyone, not just to the engineering students.

\section{The Aeronautics Curriculum and the Aircraft Design Courses}

The aircraft and engine design courses at the U.S. Air Force Academy are taught over the course of an academic year, beginning with $\mathrm{AE}$ 481, Introduction to Aircraft and Engine Design, which teaches cadets the basics of conceptual design. In the second semester, cadets choose whether to take AE 482, Aircraft Design, or AE 483, Aircraft Engine Design. Prior to taking these capstone design courses, the cadets have a good grounding in aerodynamics, propulsion systems, flight mechanics, and for a number of cadets, flight testing (see [4-7] for an overview of the department and some of the background education received by the cadets).

An overall purpose of the design sequence is to teach the cadets about the nine technologies in the conceptual design process: "customer focus, design synthesis and geometry modeling, engineering drawing, aerodynamic analysis, constraint analysis, mission analysis, sizing, optimization, and performance and cost reporting are essential tools which the aircraft design student must learn in order to practice conceptual design [8]."

In the second semester course the cadets begin preliminary design and analysis of their systems and concepts. In Aircraft Design a fairly high level of analysis must be accomplished, including structural design (often using finite element analysis), control system design, detailed aerodynamics (often including CFD simulation of the configuration), as well as weight and balance, landing gear, and performance analysis of the aircraft. In Aircraft Engine Design a complete engine cycle analysis and design is accomplished, including designing all major components of an engine and analysis of performance. Typically, the Aircraft Design and Aircraft Engine Design courses are run separately, although some level of coordination can exist, depending on the design project. 


\section{Engineering 410}

Every cadet graduating from the USAF

Academy receives a Bachelor of Science degree, whether they major in science and engineering or the humanities and social science. As part of the core curriculum, each cadet takes six engineering courses. For the last 31 years, the USAF Academy has offered a senior-level engineering systems design course, Engr. 410 that ties the other core engineering courses together. "The course is designed to introduce cadets of all majors to the engineering design process and the Air Force acquisition process. The cadets are expected to apply knowledge from past courses at the United States Air Force Academy to design, build, test, and deliver a project that the instructor assigns to them, which benefits a realworld user [9]." During the course of the semester, the cadets meet certain milestones, give briefings and demonstrations, and prepare technical reports. The course was created, "so that technical and non-technical cadets can team up to perform meaningful work in an engineering design format. In the midst of a unique and often challenging group dynamics environment, the cadets are challenged to find their own solution to an ill-defined problem, and then actually perform hands on fabrication and testing of their project [9]."

The Engr. 410 course had a wide variety of curricular outcomes, all of which had to be tied into the work being conducted by the aircraft and engine design teams. The outcomes for the course were [9]:

1. Define and explain the phases of the DoD Acquisition process and identify associated milestones

2. Given a request for proposal (RFP), you should be able to:

a. validate the user's requirements and present various design alternatives, highlighting how each will meet the user's requirements

b. develop a technical, cost and management proposal that will demonstrate how your selected design will be developed through studies, engineering analysis, subsystem fabrication, system integration, and testing.
3. Once a design has been selected, demonstrate through oral and written presentation that it meets the user's specifications

4. Demonstrate independent learning by identifying and researching unknown information dealing specifically with your project (i.e. safety standards, building materials, hazardous materials)

5. Demonstrate competence in the timely and professional completion of your task by creating a schedule to meet all required milestones

6. Demonstrate competence in teamwork by ensuring that all team members are gainfully employed to meet all required tasks

7. Demonstrate competence in resource management by completing your project within budget and material constraints.

The Engr. 410 course roadmap is shown in Fig. 1, which mimics the stages that take place on programs in the Air Force. A more detailed discussion of how this was applied to the aircraft design will follow.

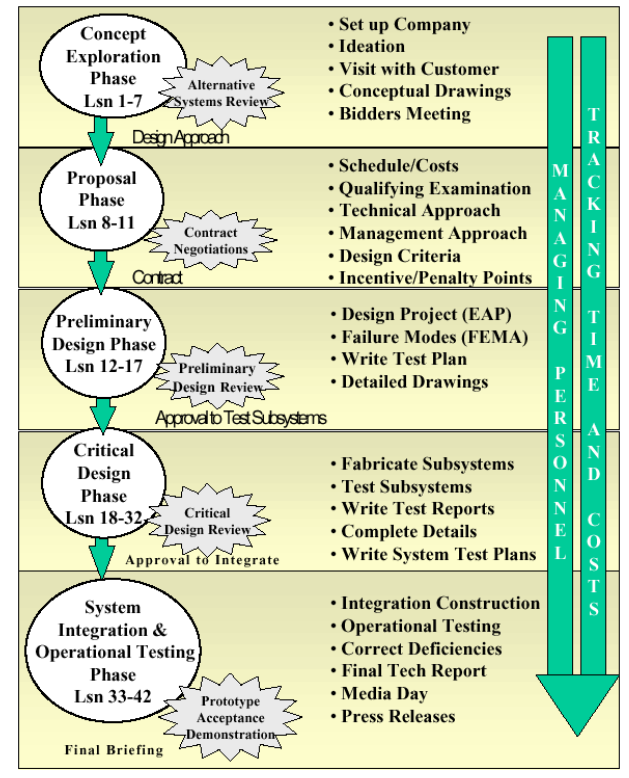

Figure 1. Engineering 410 Roadmap (from [9])

\section{The Experiment}

One of the major problems facing engineering educators today is the difficulty in supplying students with a truly multi-disciplinary 
experience. It is fairly easy to say that an aircraft or engine is a multi-disciplinary design project (which is true), but students aren't necessarily forced to deal with issues and perspectives outside of their major. It would be somewhat more difficult, due to university logistics and department inertia, to give students a design experience that required working with other engineering students, perhaps attempting to merge the ideas and analysis of aerospace, mechanical, civil, electrical, and industrial engineering students (see [10-12] for example). However, at most universities it would be unthinkable to have a multidisciplinary design course or project that attempted to integrate students from engineering, science, humanities, and social science backgrounds! It is just such a course that was attempted in Spring 2002 at the U.S. Air Force Academy.

Earlier in the year we decided to allow two of our aircraft design teams to work on the RFP for the AIAA Foundation Undergraduate Team Aircraft Design competition. Instead of simply allowing these groups of Aircraft Design cadets to work on the project alone, we decided to also incorporate the cadets from Aircraft Engine Design into the teams. Each team would consist of five cadets from the Aircraft Design course and five cadets from the Aircraft Engine Design course. Finally, we also decided to supplement these groups with a group of cadets from Engr. 410 - their contribution would be to design, build, and potentially fly a scale model of the fighter aircraft being designed by the aeronautics cadets. The end product would be a validation model that could provide basic performance and stability information about the aircraft at low speeds, especially during takeoff and landing.

While the outcomes for Engr. 410 (see previous section) may seem aggressive in scope, they tied in well with the goals we had for our design students, thereby making it possible for the "design" students to work on the same schedule as the "build" students, with both groups working toward solving a common overall problem.

The course began with a concept exploration phase (see Fig. 1), which in our case was tied to how the cadets would build a model airplane and to discover the technologies that would enable them to complete their aircraft. The Engr. 410 cadets investigated structures, propulsion, landing gear, electrical \& radio systems, and cost issues at this preliminary phase. As the cadets proceeded through the various phases shown in Fig. 1, they interacted with the aircraft design cadets for help in understanding the technical issues involved with their decisions.

At the very beginning phase the cadets were also asked to organize themselves into a "company" and to choose roles for all of the members of the team. Figure 2 shows the organization chart for the team. Students were encouraged to choose a job that would take advantage of their educational background, with management and social science majors working on finance and public affairs, science and engineering majors working on the aircraft construction, and other majors filling in as deemed appropriate.

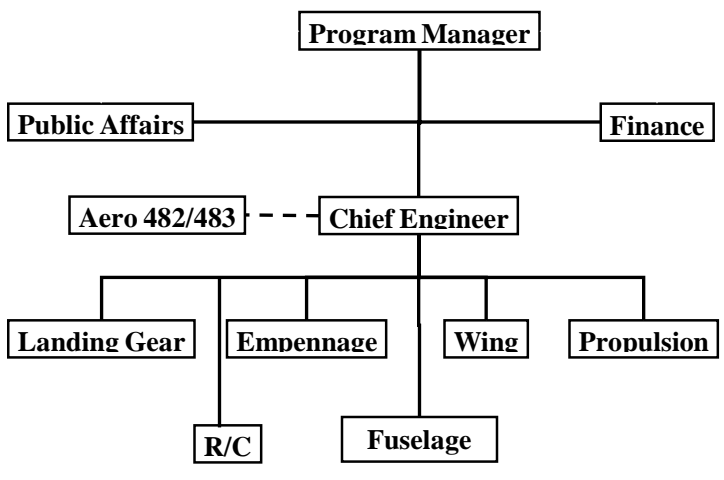

Figure 2. Organization Chart

This required technical and non-technical students to communicate about a technical subject, requiring a relatively high level of team organization and patience, including fairly detailed scheduling to insure coordination among the various groups involved. The cadets quickly discovered that effective communication was key to insuring coordination among three groups of people (aircraft design, aircraft engine design, and model construction), so they created a team web page where schedules, plans, and current status of work could be shared (see Fig. 3). 


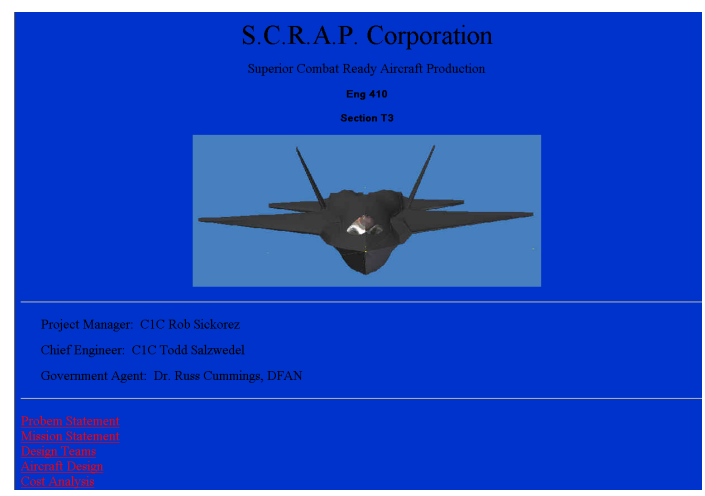

Figure 3. Construction Team Web Page

communicating among the various groups needed to take place. At first, this was quite difficult, with the aircraft design cadets viewing the model construction team as a "nuisance." Questions from the model construction team such as, "where should the landing gear be placed?" and "how big does the wing have to be?" went unanswered for awhile, but slowly the aircraft design cadets began to teach the nontechnical cadets how to size, place, and shape various portions of the aircraft. By the end of the semester, some of the model construction team members were quite proficient at certain technical tasks, such as the rules of thumb for sizing and placing landing gear and the construction techniques for radio-controlled aircraft.

As the semester progressed, the construction team was also frustrated by a very real design dilemma-they wanted start working on the more advanced aspects of constructing the aircraft, but the aircraft and engine design teams were not done iterating on their designs. How, the construction team wondered, could they prepare to build an airplane if they did not know what its external shape was going to be? We are sure that similar difficulties arise in manufacturing all the time, but knowing that they were experience real-world problems did not make the situation any easier for the construction team.

Finally, however, a relatively "converged" design was arrived at by the aircraft and engine teams, and the construction cadets began building their radio-controlled model. The various construction sub-discipline teams now had to face the reality of insuring that their various portions of the aircraft (wing, fuselage, radio, engine, etc.) were going to be constructed as a single, unified airplane rather than a set of unrelated parts. A number of meetings were held to insure that compatible systems were being designed, and that the parts of the airplane would mesh during construction. Cadets from the aircraft and engine design teams were encouraged to participate once construction began, and the camaraderie between the teams increased a great deal when they finally saw the airplane being constructed. Representative pictures of the construction team at work are presented in Figs. 4-7, including views of the fuselage, wing, radio controls, and final aircraft.

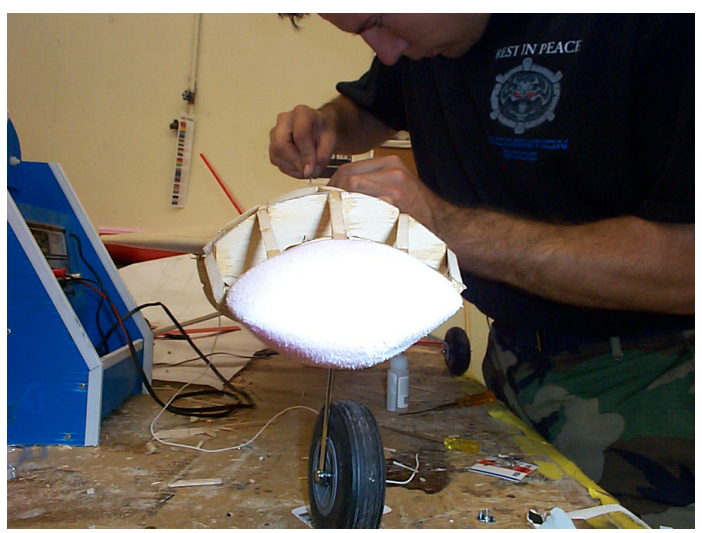

Figure 4. Starting the Fuselage

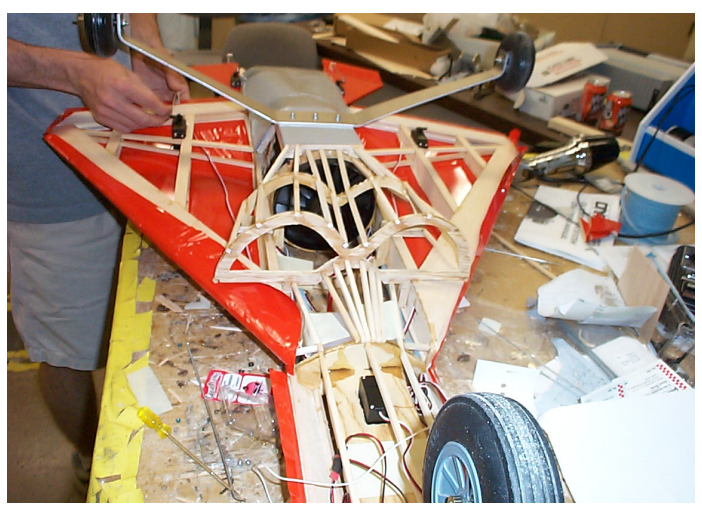

Figure 5. Wing Attachment with Monokote Being Added 


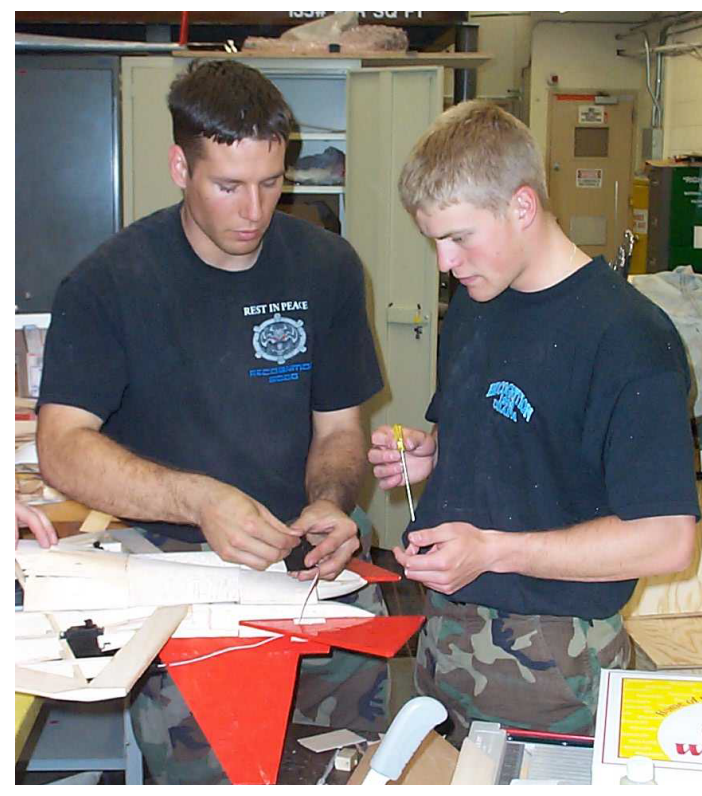

Figure 6. Control Servos and Electrical System Being Installed

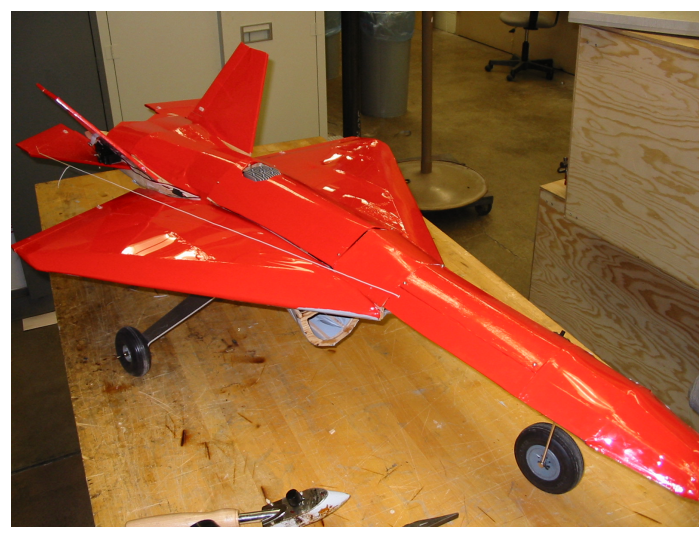

Figure 7. Final Aircraft Prior to Taxi Testing

At this point in the design and construction process, the cadets were slightly (but not significantly) behind schedule, and while it was unlikely they would have time to fly their aircraft, a high level of pride became evident in the teams. A last minute rush of hard work enabled the aircraft to be completed and a successful taxi test was conducted (see Fig. 8). With just a few more days of work the teams would have their aircraft flying!

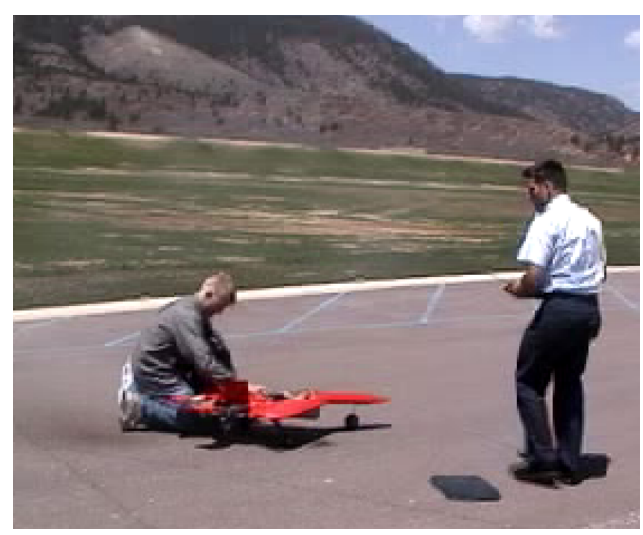

Figure 8. Cadets Taxi Testing The Fighter-Bomber Model

\section{$\underline{\text { Assessment }}$}

A variety of assessment tools are available to determine the relative level of success of our experiment. While no formal assessment was given, a number of course assessment information is available. In addition to observations by the faculty, cadets were interviewed twice, and evaluated each other twice. Many of the problems we discuss in the following section (Lessons Learned) became apparent from this input. A fair amount of frustration took place among the three groups, with each group waiting for the work of the other groups-a typical problem in industry. As the semester progressed, with input from the faculty, the cadets began to realize that they could continue working even if they only had preliminary information from the other groups.

While we can't claim total success in the resulting aircraft design in the AIAA team aircraft design competition, the designs were very good for first efforts by a university. A total of twenty designs were submitted for judging in the competition, and the Academy design was rated very high, just below the second and third place teams. The teams that won the competition (from Cal Poly and Virginia Tech) have been participating in the design competition for many years, with a long history of excellent results on which to build. The Academy team did very well considering our inexperience in the competition. While most of the judge's comments were technically oriented, a few comments addressed the ingenuity and design traits of the cadets: "Refreshing to see an original design and not a re-tooled F-22 or YF23 (which are wrong configurations for this 
mission anyway)"; "Good originality and excellent approach to a difficult RFP. Imagination and creativity were evident throughout the design process"; and "The team's decision to use a single engine in a survivable deep strike aircraft is original, albeit controversial, too." We hope that the unique nature of the design and construction teams helped, in some small way, to make these results possible.

\section{Lessons Learned}

While we would like to be able to say that this educational experiment worked flawlessly, the truth is a little more disappointing. A variety of difficulties took place over the course of the semester, and in the interest of continuous improvement we will share them.

First of all, nearly every cadet acknowledged at the end of the semester that communication was the required key ingredient for running a successful project-intra-group communication within the three groups and inter-group communication as well. A great deal of instructor time was required to insure that the cadets were working together, since it was obvious fairly early that a strong "us vs. them" mentality was developing between the groups.

This problem came to a climax fairly early in the term and required a group brain-storming session to find ways to alleviate the problem. The cadets decided to "assign" liaisons between the groups at many levels, not just at the "top" as shown in the original organization chart (see Fig. 2) where only the Chief Engineer interacted with the "CEO" of the other groups. Each sub-discipline within the groups had a direct contact from the other groups, such as the model team's landing gear cadets working directly with the aircraft design team's landing gear "expert".

Along similar lines, while the cadets realized how important communication was to success, they didn't always have the "tools" and experience to share knowledge and ideas with each other (and cadets at military academies are typically very good at working in teams). Learning to speak and write to people who don't share your knowledge base and experience can be challenging for anyone-we hope that the experience the cadets received from this experience will help them in future situations.
Another area that did not work as well was in the relation between the aircraft engine design cadets and the cadets working on the engine for the radio-controlled model. The construction team decided, for a variety of reasons, to use a gaspowered ducted fan engine. Our goal was for the engine design students to work with the construction students to size and estimate the performance of the model aircraft engine. We had a great deal of difficulty getting the engine design students to explain the important aspects of the model engine and possible problem areas - we would have liked to see more interaction (and "teaching") in this area.

Finally, we noticed was the "tech" students (regardless of which group they were in) did not always respect the input and ideas of the "nontech" students. This is especially troublesome when you consider that nearly all cadets will have to interact with a variety of colleagues during the career (this would also be true of students at civilian universities after they graduate and work in industry). This difficulty is a little more troublesome, since it points to a deeper rooted problem than merely "group think" among various teams. While we weren't able to effectively deal with these attitudes, we hope that the cadets will realize that large projects require the effective participation of a wide variety of people, from technicians to scientists, accountants to marketers, janitors to program directors.

\section{Conclusions}

A dilemma has faced engineering educators in recent years as accreditation, government, and industry pressures have forced faculty to reexamine how and when they teach design. Traditional engineering programs viewed design as a poor stepchild, often relegated to secondclass status in research-dominated departments. In addition, design courses were seen as being purely an application of material that the students were taught in previous (or concurrent) courses.

A multifaceted, novel approach to improving this situation was attempted at the U.S. Air Force Academy in conjunction with the AIAA Foundation Undergraduate Team Aircraft Design Competition. Three groups were involved for each airplane: the first group was responsible for the airframe, the second group was responsible for the engine, and the third group was responsible for the construction and flight testing 
of a radio-controlled flying model. Students from a variety of majors, both technical and nontechnical, participated in various aspects of the project. This approach is seen as one method to give students a multidisciplinary approach to design and problem solving.

\section{$\underline{\text { References }}$}

1. Furgason, R.R., "Update on ABET Accreditation Activities," ABET Memo to Engineering Deans, April 1994.

2. "Criteria for Accrediting Engineering Programs, 2001-2002 Accreditation Cycle," Engineering Accreditation Commission, Accreditation Board for Engineering \& Technology, Baltimore, 2001.

3. Nicolai, L.M., "An Industry View of Engineering Design Education," AIAA Paper 93-0328, Jan. 1993.

4. Barlow, D., Nowlin, S., and Bossert, D., "Falcons Soaring: USAFA Department of Aeronautics Contributions to Aerospace Power During a Century of Manned Flight," AIAA Paper 20020564, Jan. 2002.

5. Bossert, D.E., and Yechout, T.R., "A MATLAB-Based Flight Simulator for Flight Mechanics Education," AIAA Paper 2002-4876, Aug. 2002.

6. Haven, B.A., Byerley, A.R., and Barlow, D.N., “An Undergraduate Gas Turbine Engine Program Enhanced by Design and Research Trends," ASME Paper GT-2002-30588, June 2002.

7. Wolf, J., and Sansone, A., "The U.S. Air Force Academy's Flight Test Course: Preparing Tomorrow's Flight Testers," AIAA Paper 2002-1048, Jan. 2002.

8. Crisler, W.P., and Brandt, S.A., "Teaching the Nine Technologies of Conceptual Aircraft Design," World Aviation Congress, Paper 98WAC-138, Sep. 1998.

9. Bayley, D., Lawrence, T., and Warner, M., "The Capstone Engineering Systems Design Process at the United State Air Force Academy," ASEE Annual Conference, 2001.

10. Frederick, R.A., Pawlak, M.S., Ultey, D.M., Corsetti, C.D., Wells, B.E., and Landrum, D.B., "International Product Teams for Aerospace System Design," AIAA Paper 2002-4337, July 2002.
11. Cummings, R.M., and Freeman, H.J.A., "Integrating Multidisciplinary Design in an Undergraduate Engineering Curriculum," SAE Transactions, Vol. 106, No.1, 1997, pp. 1665-1670.

12. Kettering, M.L., and Biezad, D.J., "The Roadable Aircraft Design Project," AIAA Paper 96-4071, Sept. 1996. 